BP, VT and RE) and with IXE Q2W for PCS, MCS, and 7/8 domains (except MH) (post hoc). Within the same subgroup, a greater percentage of pts in each of the 3 active groups reported SF-36 scores $\geq$ normative values at Wk 24 vs PBO, with statistical significance for PCS, MCS, and majority of the individual domains (Table) (post hoc).

Table 1. Percentage of patients with SF-36 scores $\geq$ normative values at week 24 (n) among the patients reporting SF-36 scores $<$ normative values at baseline (N) (nonresponder imputation)

\begin{tabular}{lcccc}
\hline SF-36 Scores, n/N (\%) & PBO & ADA & IXEQ4W & IXEQ2W \\
\hline Physical Component Summary & $4 / 101(4.0)$ & $20 / 93\left(21.5^{\dagger}\right)$ & $12 / 98\left(12.2^{\star}\right)$ & $19 / 95\left(20.0^{\star \star}\right)$ \\
Mental Component Summary & $10 / 53(18.9)$ & $21 / 52\left(40.4^{\star}\right)$ & $21 / 58\left(36.2^{*}\right)$ & $21 / 55\left(38.2^{\star}\right)$ \\
Physical Functioning Domain & $5 / 94(5.3)$ & $22 / 91\left(24.2^{\dagger}\right)$ & $14 / 97\left(14.4^{\star}\right)$ & $19 / 87\left(21.8^{\star \star}\right)$ \\
Role Physical Domain & $5 / 98(5.1)$ & $19 / 91\left(20.9^{\star \star}\right)$ & $16 / 93\left(17.2^{\star}\right)$ & $19 / 86\left(22.1^{\star \star}\right)$ \\
Bodily Pain Domain & $12 / 95(12.6)$ & $28 / 87\left(32.2^{\star \star}\right)$ & $27 / 96\left(28.1^{*}\right)$ & $28 / 93\left(30.1^{\star \star}\right)$ \\
General Health Domain & $8 / 97(8.2)$ & $14 / 88(15.9)$ & $16 / 92(17.4)$ & $21 / 91\left(23.1^{\star}\right)$ \\
Vitality Domain & $11 / 73(15.1)$ & $22 / 71\left(31.0^{*}\right)$ & $28 / 87\left(32.2^{\star}\right)$ & $22 / 74\left(29.7^{\star}\right)$ \\
Social Functioning Domain & $15 / 72(20.8)$ & $22 / 66(33.3)$ & $21 / 68(30.9)$ & $28 / 68\left(41.2^{\star}\right)$ \\
Role Emotional Domain & $7 / 54(13.0)$ & $17 / 59\left(28.8^{\star}\right)$ & $23 / 66\left(34.8^{\star}\right)$ & $27 / 64\left(42.2^{\dagger}\right)$ \\
Mental Health Domain & $17 / 69(24.6)$ & $19 / 62(30.6)$ & $18 / 69(26.1)$ & $24 / 68(35.3)$
\end{tabular}

${ }^{*} p<0.05 ;{ }^{* *} p<0.005 ;{ }^{\dagger} p \leq 0.001$.

Figure: SF-36 domain scores at baseline, Weeks 12 and 24, compared with age- and gender-matched normative scores
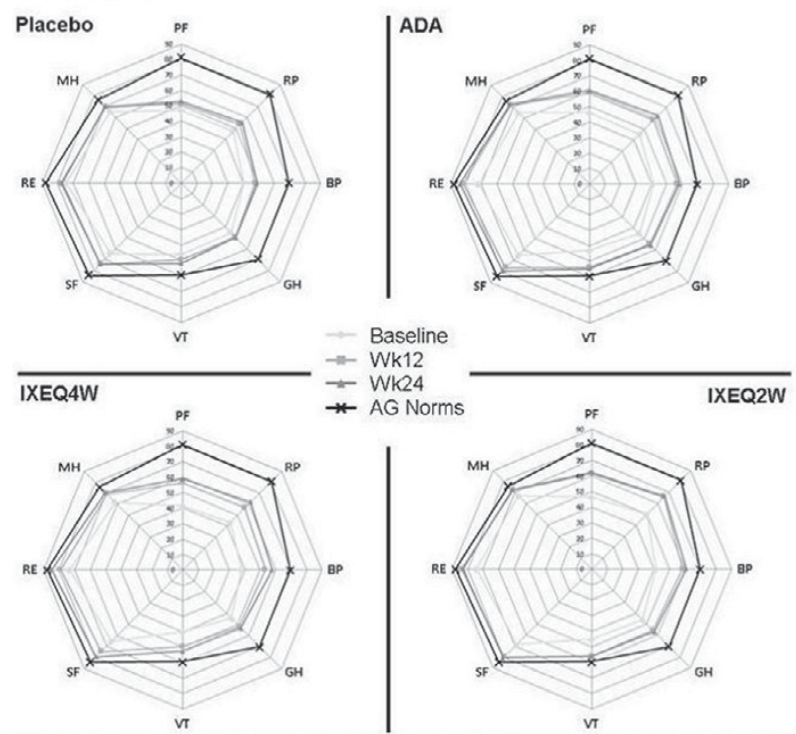

PF, Physical Functioning; RP, Role Physical; BP, Bodily Pain; GH, General Health; VT, Vitality; SF, Social Functioning; RE, Role Emotional MH, Mental Health; PCS, Physical Component Score; MCS, Mental Component Score; AG norms, age-and gender-normalized; ADA, MH, Mental Health; PCS, Physical Component Score; MCS, Mental Co
adalimumab; BL, baseline; IXE, ixekizumab; PBO, placebo; Wk, week

Conclusions: In pts with active PSA, both IXE and ADA treatment groups reported significant improvements in pt-reported health status as assessed by SF-36 and the majority of its individual domains, both in the general trial population, and in the subgroup of pts with baseline scores $<A / G$ norms. References:

[1] Mease PJ et al. ARD, 2017, 76(1):79-87.

[2] Ware J, et al. How to score version 2 of the SF-36 health survey. Lincoln, RI: QualityMetric Inc.; 2000.

Disclosure of Interest: V. Strand Consultant for: Eli Lilly and Company, Abbvie, Amgen, BMS, Boehringer Ingelheim, Celltrion Corrona, EMDSerono, GSK, Janssen, Merck, Novartis, Pfizer, Regeneron, Sandoz, Sanofi, UCB, A. Gottlieb Grant/research support from: Centocor (Janssen), Amgen, Abbott (Abbvie), Novartis, Celgene, Pfizer, Lilly, Levia, Merck, Xenoport, Dermira, Baxalta, Consultant for: Amgen Inc.; Astellas, Akros, Centocor (Janssen), Inc.; Celgene Corp., Bristol Myers Squibb Co., Beiersdorf, Inc., Abbott Labs. (Abbvie), TEVA, Actelion, UCB, Novo Nordisk, Novartis, Dermipsor Ltd., Incyte, Pfizer, Canfite, Lilly, Coronado, Vertex, Karyopharm, CSL Behring Biotherapies for Life, Glaxo Smith Kline, Xenoport, Catabasis, Meiji Seika Pharma Co., Ltd, Takeda, Mitsubishi,Tanabe Pharma Development America, Inc, Genentech, Baxalta, Kineta One, KPI Therapeutics, Crescendo Bioscience, Aclaris, Amicus, Reddy Labs, T. Kvien Consultant for: AbbVie, Biogen, BMS, Boehringer Ingelheim, Celltrion, Eli Lilly, Epirus, Janssen, Merck-Serono, MSD, Mundipharma, Novartis, Oktal, Orion Pharma, Hospira/Pfizer, Roche, Sandoz and UCB, Speakers bureau: AbbVie, Biogen, BMS, Boehringer Ingelheim, Celltrion, Eli Lilly, Epirus, Janssen, Merck-Serono, MSD, Mundipharma, Novartis, Oktal, Orion Pharma, Hospira/Pfizer, Roche, Sandoz and UCB, A. Naegeli Employee of: Eli Lilly and Company, C.-Y. Lin Employee of: Eli Lilly and Company, O. Benichou Employee of: Eli Lilly and Company, J. Birt Employee of: Eli Lilly and Company

DOI: 10.1136/annrheumdis-2017-eular.2331

\section{AB0794 EFFECT OF TOFACITINIB ON PATIENT-REPORTED OUTCOMES IN PATIENTS WITH ACTIVE PSORIATIC ARTHRITIS: RESULTS FROM TWO PHASE 3 STUDIES}

V. Strand ${ }^{1}$, K. de Vlam ${ }^{2}$, J.A. Covarrubias-Cobos ${ }^{3}$, P.J. Mease ${ }^{4}$, D.D. Gladman ${ }^{5}$, T. Hendrikx ${ }^{6}$, E. Kudlacz ${ }^{7}$, D. Graham ${ }^{7}$, J. Wu ${ }^{7}$, L. Chen ${ }^{8}$. ${ }^{1}$ Division of Immunology/Rheumatology, Stanford University, Palo Alto, CA, United States; ${ }^{2}$ UZ Leuven, Leuven, Belgium; ${ }^{3}$ Unidad Reumatologica Las Americas S.C.P., Mérida, Yucatán, Mexico; ${ }^{4}$ Swedish Medical Center and University of Washington, Seattle, WA, United States; ${ }^{5}$ Department of Medicine, University of Toronto, Toronto Western Hospital, Toronto, ON, Canada; ${ }^{6}$ Pfizer Inc, Collegeville, PA; ${ }^{7}$ Pfizer Inc, Groton, CT; ${ }^{8}$ Pfizer Inc, New York, NY, United States

Background: Tofacitinib is an oral Janus kinase inhibitor under investigation for treatment of psoriatic arthritis (PsA). The safety and efficacy of tofacitinib for the treatment of PsA has been investigated in two Phase 3 randomised controlled trials (RCTs: OPAL Broaden [12 months; NCT01877668]; OPAL Beyond [6 months; NCT01882439]).

Objectives: To evaluate patient-reported outcomes (PROs) in patients (pts) with active PsA enrolled in OPAL Broaden ( $N=422$ ) and OPAL Beyond ( $N=394)$. OPAL Broaden pts had an inadequate response (IR) to $>1$ conventional synthetic disease-modifying antirheumatic drug and were naïve to tumour necrosis factor inhibitors (TNFi) whilst OPAL Beyond pts had an IR to $\geq 1$ TNFi.

Methods: Pts were randomised to tofacitinib $5 \mathrm{mg}$ twice daily (BID), tofacitinib $10 \mathrm{mg} \mathrm{BID}$, placebo $(\mathrm{PBO}) \rightarrow$ tofacitinib $5 \mathrm{mg} \mathrm{BID}, \mathrm{PBO} \rightarrow$ tofacitinib $10 \mathrm{mg}$ BID and, in OPAL Broaden, also to adalimumab $40 \mathrm{mg}$ subcutaneously every two weeks (active comparator). Pts receiving PBO advanced to either tofacitinib 5 $\mathrm{mg}$ BID or $10 \mathrm{mg}$ BID at month 3 (M3) in both RCTs. Least squares mean changes from baseline in: Patient's Global Assessment of Arthritis (PtGA; Visual Analogue Scale [VAS]); Arthritis Pain (Pain; VAS); Short Form-36 Health Survey (SF-36); Functional Assessment of Chronic Illness Therapy-Fatigue (FACIT-F); Dermatology Life Quality Index (DLQI) and Ankylosing Spondylitis Quality of Life (ASQOL) questionnaires are reported. Nominal $p$ values are reported without adjustments for multiple comparisons.

Results: Patients with active PsA in OPAL Broaden and OPAL Beyond RCTs receiving tofacitinib $5 \mathrm{mg}$ and $10 \mathrm{mg}$ BID reported improved PROs compared with PBO (Table 1). Greater improvements in PtGA and Arthritis Pain were observed as early as Week 2 through M3 with both tofacitinib doses compared with PBO in both studies $(p \leq 0.05)$. Greater improvements were also reported in SF-36 Physical Component Summary, DLQI and ASQOL scores at M1 and M3 with both tofacitinib doses compared with PBO $(p<0.05)$. There were greater improvements in SF-36 physical functioning, bodily pain and vitality domains with both tofacitinib doses compared with PBO in both studies $(p \leq 0.05)$ at M3. SF-36 social functioning domain showed greater improvement with tofacitinib $5 \mathrm{mg}$ BID in OPAL Broaden and both tofacitinib doses in OPAL Beyond compared with PBO at M3 $(p \leq 0.05)$. SF-36 role-physical domain showed greater improvement with tofacitinib $10 \mathrm{mg}$ BID in OPAL Beyond at M3 compared with PBO $(\mathrm{p}<0.05)$. FACIT-F showed a greater improvement in both studies at M3 with both tofacitinib doses compared with PBO $(p \leq 0.05)$. In OPAL Broaden, improvements in PROs were similar between tofacitinib and adalimumab.

Table 1. PROs at Baseline and Change from Baseline (A) at Month 3

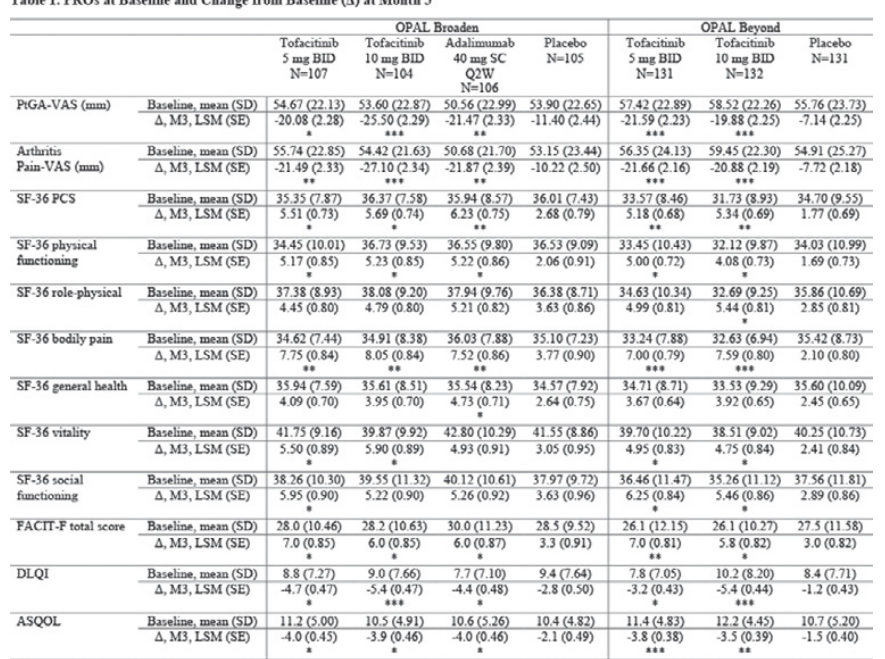

"Nominal $\mathrm{p} \leq 0.05 ; \cdots p<0.001 ; \cdots$ p 0.0001 . Other variables assessed as not achieving $\mathrm{p} \leq 0.05$ at M3 were SF-36 Mental Component Summary (MCS), mental health and role emotional domain scores

Nis the number of patients who were randomised and received at least one dose of study medication. A subject was excluded from an analysis for an endpoint if the baseline was missing or there was no post-baseline observation

$\triangle$, change from baseline; ASQOL, Anlylosing Spondylitis Quality of Life; BID, twice daily, DLQI, Dermatology Life Quality Index; FACrT-F, Functional Assessment of Chronic Illness Therapy-Fatigue; LSM, least squares mean; M3, Month 3; PCS, Physical Component Summary, PRO, patient-reported outcome: P.GA, Patient's Global Assessment of Arthritis, Q2W, every two weeks; SC, subcutaneously, SD, standard deviation SE, standard error, SF-36, Short Form-36 Health Survey, VAS, Visual Analogue Scale 
ments in PROs compared with $\mathrm{PBO}$ at $\mathrm{M} 3$ that were maintained throughout both RCTs.

Acknowledgements: To be presented at AAD 2017 and reproduced with permission. This study was sponsored by Pfizer Inc. Editorial support was provided by S. Morgan of CMC and was funded by Pfizer Inc.

Disclosure of Interest: V. Strand Consultant for: AbbVie, Amgen, Bristol-Myers Squibb, CORRONA, Eli Lilly, Janssen, Novartis, Pfizer Inc, UCB, K. de Vlam Consultant for: Celgene, Eli Lilly, Janssen, Novartis, Pfizer Inc, UCB, Speakers bureau: Celgene, Eli Lilly, Janssen, J. Covarrubias-Cobos Grant/research support from: Bristol-Myers Squibb, Eli Lilly, Janssen, Pfizer Inc, P. Mease Grant/research support from: AbbVie, Amgen, Bristol-Myers Squibb, Celgene, Eli Lilly, Janssen, Novartis, Pfizer Inc, Sun, UCB, Consultant for: AbbVie, Amgen, Bristol-Myers Squibb, Celgene, Crescendo, CORRONA, Dermira, Janssen, Eli Lilly, Merck, Novartis, Pfizer Inc, Sun, UCB, Zynerba, Speakers bureau: AbbVie, Amgen, Bristol-Myers Squibb, Celgene, Crescendo, Genentech, Janssen, Novartis, Pfizer Inc, UCB, D. D. Gladman Grant/research support from: Amgen, AbbVie, BristolMyers Squibb, Celgene, Janssen, Eli Lilly, Pfizer Inc, Novartis, UCB, Consultant for: Amgen, AbbVie, Bristol-Myers Squibb, Celgene, Janssen, Eli Lilly, Pfizer Inc, Novartis, UCB, Speakers bureau: Amgen; AbbVie; Bristol-Myers Squibb; Celgene; Janssen; Eli Lilly; Pfizer Inc; Novartis; UCB, T. Hendrikx Shareholder of: Pfizer Inc, Employee of: Pfizer Inc, E. Kudlacz Shareholder of: Pfizer Inc, Employee of: Pfizer Inc, D. Graham Shareholder of: Pfizer Inc, Employee of: Pfizer Inc, J. Wu Shareholder of: Pfizer Inc, Employee of: Pfizer Inc, L. Chen Shareholder of: Pfizer Inc, Employee of: Pfizer Inc

DOI: 10.1136/annrheumdis-2017-eular.2445

\section{Osteoarthritis}

\section{AB0795 OSTEOARTHRITIS AND COMORBIDITY: ASSOCIATION BETWEEN MENTAL FEATURES AND CYTOKINES LEVELS}

\section{E. Trifonova, O. Sazonova, E. Zonova. Novosibirsk State Medical University,} Novosibirsk, Russian Federation

Background: Studies of mental health in patients with osteoarthritis (OA) are topical at the present time. This applies especially to OA patients with such comorbidity as obesity, metabolic syndrome (MS) and type 2 diabetes mellitus (T2DM). Psychological features, quality of life $(\mathrm{Q} o \mathrm{~L})$ and depression degree also can be linked with immunopathogenesis of OA with obesity, MS, T2DM.

Objectives: To explore the mental health in knee OA patients with obesity, MS, T2DM and to estimate association between psychological and immunological features.

Methods: Patients $(n=128)$ with bilateral knee OA according to ACR criteria were divided into four groups. Group $1(n=17)$ had obesity, group $2(n=17)$ had MS, group $3(n=56)$ had T2DM and group $4(n=38)$ had only knee OA without comorbidity. All patients were comparable by age, sex and duration of $\mathrm{OA}$. We assessed serum cytokine levels (IL-1b, IL-6, IL-10, IL-18), NO and adipokines (adiponectin, leptin) using ELISA. The parameters of QoL, mental health and depression degree were measured by short form 36 (SF-36), Knee injury and Osteoarthritis Outcome Score - (KOOS) and with patient health questionnaire-9 (PHQ-9). We also studied coping strategies to overcome pain by Coping Strategy Questionnaire (CSQ). U-Mann-Whitney test was applied to detect differences between groups. Correlation was assessed using Spearman correlation coefficient $\left(r_{\mathrm{s}}\right)$.

Results: During comparative analysis, we found many statistically significant differences in such indexes and questionnaires as SF-36, KOOS, PHQ-9, CSQ between groups knee OA patients with comorbidity and group knee OA patients without concomitant diseases. Patients with $\mathrm{OA}$ and obesity were characterized by low values of mental health (SF-MH) (median (Me) 52; interquartile range (IQR) 38-64; $p=0.01$ ). Patients from group 2 (MS) and 3 (T2DM) had significant impairment of QoL parameters, mental health values. Patients of these groups also had the higher degree of depression and built coping strategies to overcome

Table. Correlations between mental parameters and serum cytokine levels in studied groups.

\begin{tabular}{|c|c|c|c|c|}
\hline \multirow[t]{2}{*}{ Cytokines } & \multirow{2}{*}{ 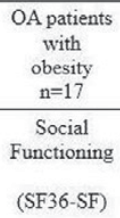 } & \multicolumn{3}{|c|}{$\begin{array}{c}\text { OA patients } \\
\text { with } \\
\text { T2DM } \\
\mathrm{n}=56\end{array}$} \\
\hline & & $\begin{array}{l}\text { Vitality } \\
\text { (SF36- VT) }\end{array}$ & $\begin{array}{c}\text { Social } \\
\text { Functioning } \\
\text { (SF36-SF) }\end{array}$ & $\begin{array}{l}\text { Coping Strategy } \\
\text { Questionnaire } \\
\text { (CSQ) }\end{array}$ \\
\hline $\mathrm{IL}-1 \mathrm{~B}(\mathrm{pg} / \mathrm{ml})$ & -0.51 & -0.06 & 0.08 & -0.15 \\
\hline $\mathrm{IL}-6(\mathrm{pg} / \mathrm{ml})$ & $-0.89^{*}$ & $-0.33^{*}$ & $-0.27^{\star}$ & -0.03 \\
\hline IL-10 (pg/ml) & -0.75 & -0.18 & -0.09 & $-0.41^{*}$ \\
\hline $\mathrm{NO}(\mathrm{pg} / \mathrm{ml})$ & -0.39 & 0.10 & 0.14 & 0.11 \\
\hline Leptin ( $\mathrm{ng} / \mathrm{ml})$ & -0.27 & $-0.28^{*}$ & -0.22 & $0.43^{*}$ \\
\hline
\end{tabular}

Table legend: ${ }^{*} \mathrm{r}-\mathrm{p}<0.005$; pain of $O A$ worse than patients of $O A$ group. Differences in serum cytokine levels were found in patients with OA and T2DM (IL-6 p=0.0018; IL-18 p=0.0006; NO $p<0.001)$. Significant high leptin level had OA patients with obesity $(p=0.03)$ and OA patients with T2DM $(\mathrm{p}=0.0002)$. Correlation analysis identified the association between mental health and cytokines in OA patients with obesity and OA patients with T2DM. Some data are presented (Table).

Conclusions: This study suggests that OA patients with obesity, MS and T2DM have special mental features which may be linked with immunological parameters. This data should be verified by larger studies and can be the part for an integrated program of treatment and rehabilitation of OA patients with comorbidity.

References:

[1] Perruccio, A.V. Cross-Sectional Contrast Between Individuals With Foot/Ankle vs Knee Osteoarthritis for Obesity and Low Education on Health-Related Quality of Life/A.V. Perruccio et al. // Foot \& Ankle Int. - 2016.- Vol. 36, N 1. P. 24-32.

[2] Siervo, M. Metabolic syndrome and longitudinal changes in cognitive function: a systematic review and meta-analysis/M. Siervo et al. // J. Alzheimers Dis. 2014. - Vol. 41, N 1. - P. 151-161.

[3] Berge, L.I. Comorbidity between Type 2 Diabetes and Depression in the Adult Population: Directions of the Association and Its Possible Pathophysiological Mechanisms/L.I. Berge, T. Riise // Int. J. Endocrinol. - 2015. - Vol. 2015.

Disclosure of Interest: None declared

DOI: 10.1136/annrheumdis-2017-eular.5896

\section{AB0796 THE PREDICTIVE ROLE OF INTERLEIKINE 6 AND 10 IN IMPAIRMENT OF MENTAL HEALTH IN PATIENTS WITH KNEE OSTEOARTHRITIS AND UNCONTROLLED TYPE 2 DIABETES MELLITUS}

E. Trifonova, O. Sazonova, E. Zonova. Novosibirsk State Medical University, Novosibirsk, Russian Federation

Background: The influence of different interleukins on development and progression of osteoarthritis (OA) has been proved. However, there is lack of data on relationship between mental health and immunological features in OA patient with type 2 diabetes mellitus (T2DM).

Objectives: To estimate the relationship between mental health and the proinflammatory serum cytokine levels in patients with knee OA and T2DM depending on glycemic control.

Methods: A study was performed on 45 persons who had bilateral knee OA according to the ACR criteria and T2DM. Then patients were divided into two groups according to the compensation degree T2DM taking into account parameters of glycated hemoglobin concentrations ( $\mathrm{HbA1c}$ ) which were assessed using liquid chromatography. Group $1(n=26)$ had controlled T2DM. Group 2 $(n=19)$ had uncontrolled T2DM. All patients were comparable by age, sex and duration of OA. Serum cytokine levels (IL-1b, IL-6, IL-10, IL-18), NO, and adypokines (adiponectin, leptin) using ELISA were measured. Blood glucose level was also estimated. The parameters of QoL, mental health, depression degree and coping strategies to overcome pain were measured by short form 36 (SF-36), Knee injury and Osteoarthritis Outcome Score - (KOOS) and with patient health questionnaire-9 (PHQ-9), Coping Strategy Questionnaire (CSQ). We used U-Mann-Whitney tests to detect differences between selected groups. Correlation was assessed using Spearman correlation coefficient $\left(r_{s}\right)$.

Results: Patients with OA and uncontrolled T2DM had significant low values of role limitations due to emotional problems (SF-RE) (median (Me) 38; interquartile range (IQR) 25-52.3; $p=0.02$ ). Serum cytokines levels were not different between studied groups. Correlation analysis identified the relationships between parameters of mental health and serum cytokine levels in OA patients with uncontrolled T2DM. Certain data are presented (Table).

\begin{tabular}{|c|c|c|c|c|c|c|c|}
\hline \multirow[b]{2}{*}{ Cytokines } & \multicolumn{7}{|c|}{ 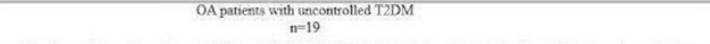 } \\
\hline & $\begin{array}{l}\text { Vitality } \\
\text { (SF36-VT) }\end{array}$ & $\begin{array}{l}\begin{array}{c}\text { Social } \\
\text { Functioning }\end{array} \\
\text { (SF36-SF) }\end{array}$ & $\begin{array}{l}\text { Mental Health } \\
\text { (SF36-MH) }\end{array}$ & $\begin{array}{l}\text { Role Emotional } \\
\text { (SF36-RE) }\end{array}$ & $\begin{array}{c}\text { General } \\
\text { Mental Health } \\
\text { (SF36-MH) }\end{array}$ & $\begin{array}{c}\text { Patient } \\
\text { Health } \\
\text { Questionnaire } \\
\text { (PHQ-9) }\end{array}$ & $\begin{array}{c}\text { Coping } \\
\text { Strategy } \\
\text { Questioanaire } \\
\text { (CSQ) }\end{array}$ \\
\hline IL-6 $6(\mathrm{pg} / \mathrm{ml})$ & $-0.60^{*}$ & $-0.62^{*}$ & $-0.54^{*}$ & .0 .25 & $-0.51^{*}$ & $0.43^{*}$ & -0.20 \\
\hline IIL-10 (pg/ml) & $-0.48^{*}$ & $-0.42^{*}$ & $-0.64^{*}$ & -0.25 & $-0.56^{*}$ & 0.29 & $-0.53^{*}$ \\
\hline No (pert) & 0.12 & 0.08 & 0.12 & $0.42^{*}$ & 031 & 0.15 & .0 .02 \\
\hline Leptin (ne ml) & .031 & $-0.42^{*}$ & .0 .14 & .0 .19 & .0 .15 & 0.28 & 0.35 \\
\hline
\end{tabular}

Table legend: $\boldsymbol{*}_{r \cdot p<0.005:}$

Conclusions: It follows from these results mental and immunology parameters of OA patients with uncontrolled T2DM can be linked. Such interleukins as IL-6 and IL-10 may play a role of potential biomarkers of mental impairment in this category of patients. These data should be verified by larger studies and may allow in future to develop programs of treatment and rehabilitation of OA patients with uncontrolled T2DM within personalized medicine.

\section{References:}

[1] Kapoor, M. Role of proinflammatory cytokines in the pathophysiology of osteoarthritis/M. Kapoor, J. Martel-Pelletier, D. Lajeunesse et al. Nat. Rev. Rheumatol. 2011;7(1):33-42. 